\title{
Based on the study of optimal pollutant control in yingkou section of daliaohe river
}

\author{
Qiucen Guo ${ }^{1}$, Hui Yang ${ }^{1 *}$, Huan $\mathrm{He}^{1}$ \\ ${ }^{1}$ School of municipal and environmental engineering, Shenyang Jianzhu University, Shenyang, Liaoning, 110168, China
}

\begin{abstract}
In view of the complexity of the river flowing into yingkou section of daliaohe river, an optimal pollutant control screening method combining the migration and degradation of toxic and harmful pollutants was proposed to improve the comprehensive scoring method. The weight factors of 10 synthetic scoring methods were proposed, and different weights were assigned to the weight factors, focusing more on the migration and degradation of pollutants. The improved comprehensive score method was used to screen 39 pollutants in the list of potential pollutants. Twelve kinds.
\end{abstract}

\section{Introduction}

The tributaries of the liao river, hun river and taizi river, join together and enter the sea separately in yingkou city, and the river after the confluence is called daliao river ${ }^{[1-}$ ${ }^{2]}$. As the main water source of yingkou city, the water quality of daliaohe river is seriously affected by the upstream huntai river system and the city's direct drainage enterprises. Compared with other rivers, the monitoring of water quality in daliao river has many influencing factors and complicated conditions. However, there are few researches on the screening of optimal controlled pollutants in daliaohe river, and the water quality monitoring indicators in recent years are mainly conventional indicators, without specific indicators. The evaluation of daliao river water quality monitoring results is one-sided. The comprehensive scoring method is applied to the screening and research of the optimal control pollutants in sichuan province, huaihe river and bohai sea.A quantitative screening method was established by applying various screening factors. The results of comprehensive evaluation have objective continuity. It is of great significance to screen the superior control pollutants in the daliaohe river system to obtain more accurate monitoring of pollutants, which provides an important basis for the safety of the daliaohe river system [3-5].

\section{Screening of optimal control pollutants in yingkou section of daliaohe river}

\subsection{Overview of pollution sources in yingkou section of daliaohe river}

Yingkou section of daliaohe mainly involves chemical industry, printing and dyeing industry, and petrochemical industry as shown in figure 1.Yingkou main large-scale direct sewage discharge enterprises include yingchuang sanzheng fine chemical co., LTD., yingkou paper mill, and yingkou west sewage treatment plant[6].From August 2010, yingkou paper mill began to discharge waste water into the paper mill reservoir for recycling, not directly into the liaohe river. Now the main direct sewage in yingkou section of daliaohe river comes from yingchuang sanzheng fine chemical co., LTD and yingkou west sewage treatment plant.

Direct discharge of chemical sewage sewage has: water composition is complex, many by-products; High pollutant content in wastewater; More poisonous and harmful substances; Biodegradable substances are abundant; Characteristics of high chromaticity of wastewater. The pollution of river water is serious, and the monitoring of sewage receiving water from chemical industry should not be dominated by conventional pollutants.

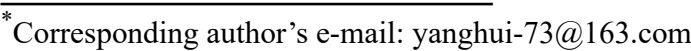




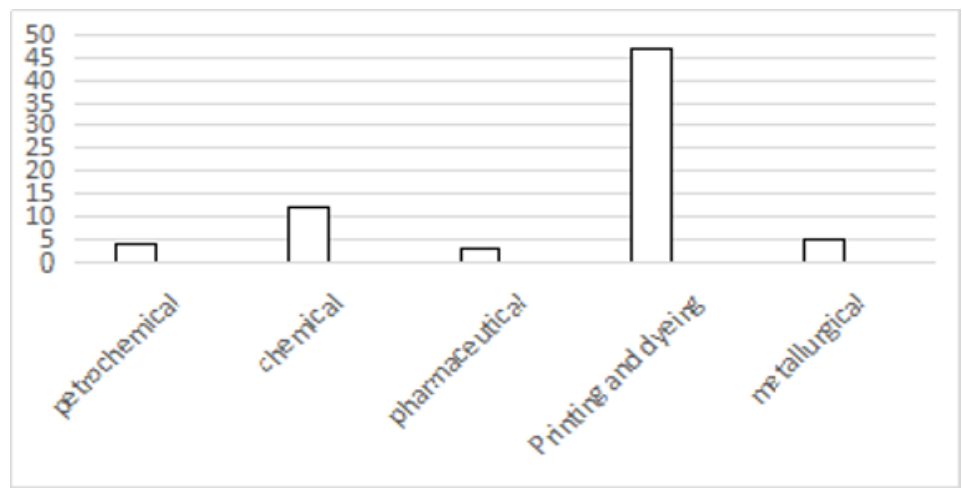

Fig1. statistics of risk enterprises in yingkou section

According to the typical pollutants in liaohe chemical industry, as shown in table 1, it is determined that there may be toxic and harmful pollutants in daliaohe river. The accumulative toxic and harmful heavy metal ions $\mathrm{Cu}, \mathrm{Pb}$, $\mathrm{Zn}, \mathrm{Cd}$ and $\mathrm{Cr}$ were listed as potential pollutants in these typical pollutants of chemical industry and daliaohe river.

Table1. typical pollutants in liaohe chemical industry

\begin{tabular}{|c|c|c|}
\hline Category & Account & Typical pollutant \\
\hline $\begin{array}{c}\text { Benzene } \\
\text { content }\end{array}$ & 14 & $\begin{array}{l}2 \text {-, } 3 \text { - nitrotoluene, } 4 \text { - nitrotoluene nitrotoluene, } 1,4 \text { - } \\
\text { dinitrobenzene, } 1,3 \text { - two nitrobenzene, } 2,5 \text {-dinitrotoluene, } 1 \text { - } \\
\text { methyl - } 2 \text {-, } 3 \text { - dinitrobenzene, } 3 \text { - amino - } 2 \text { nitrotoluene, } 1 \text { - methyl } \\
\text { - 3, } 5 \text { - dinitrobenzene, } 3,4 \text { - dinitrotoluene and } 2 \text { minus } 2 \text { - TNT, } \\
\text { amino - 4-2, } 6 \text { - dinitrotoluene, } 2 \text { - amino - } 4,6 \text { - dinitrotoluene, imine } \\
\text { biphenyl }\end{array}$ \\
\hline Phenol class & 6 & $\begin{array}{l}\text { 4-methyl-2-nitrophenol, 2-methyl-3-nitrophenol, m-nitroaniline, 4- } \\
\text { methyl-2-nitroaniline, 2-methyl-3-nitroaniline, o-methylaniline, }\end{array}$ \\
\hline Aldehyde & 2 & 2- nitrobenzaldehyde, 3- nitrobenzaldehyde \\
\hline
\end{tabular}

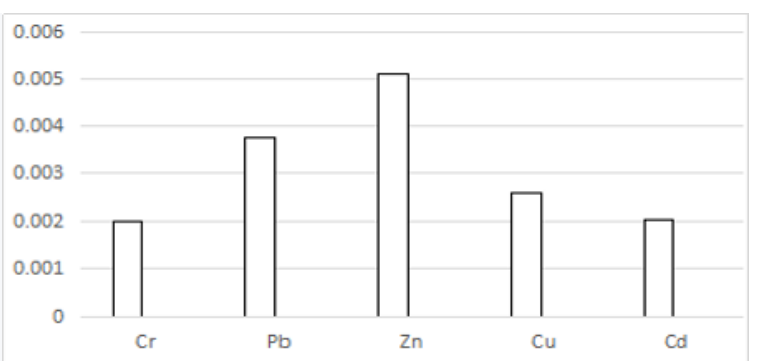

Fig2. concentration of heavy metal ions in daliaohe river

\subsection{Optimal pollutant control by migration in the upper reaches of daliao river}

Muddy too water system located in the liaohe river upstream, poisonous and harmful pollutants screening, consider not only the yingkou section of straight line of pollutants, the hun river taizi river - hun river river shelterforest, taizi river middle reaches, haicheng, shenyang, shenyang PuHe, xihe river river, benxi Yang Liuhe, majia river, 8 sections known optimal control of pollutants in the occurrences before 12 kinds of pollutants. As representative pollutants of hongtai river system, these 12 kinds of superior control pollutants in taihe tributaries are given priority to control pollutants in various industries and in multiple tributaries, which are more universal and representative, and listed as the list of potential pollutants in yingkou section of daliaohe river as shown in table 2.

Table2. occurrence frequency table of optimal control pollutants in hongtai tributary

\begin{tabular}{cccccc}
\hline Number & Pollutant name & Times & Number & Pollutant name & Times \\
\hline 1 & 2, 4-ditert-butyl phenol & 5 & 2 & 2, 4-dimethyl phenol & 5 \\
3 & 3, 5-dimethyl phenol & 5 & 4 & Diisobutyl phthalate & 5 \\
5 & Diethyl phthalate & 5 & 6 & Dimethyl phthalate & 3 \\
7 & Dibutyl phthalate & 3 & 8 & Dioctyl phthalate & 3 \\
9 & O-dimethyl dibutyl ester & 3 & 10 & Cu & 3 \\
11 & Cr & 3 & 12 & nitrobenzene & 3 \\
\hline
\end{tabular}




\subsection{Improved comprehensive scoring method}

Improve comprehensive evaluation method to pollutant migration and degradation of pollutants (B) (A), whether for liaohe typical industry pollutants (C), muddy water system optimal control of pollutants in frequency (D), liaohe potential hazard index $(\mathrm{E})$, whether it is poisonous chemicals $(\mathrm{F})$, whether to belong to the environmental hormone $(G)$, whether for the U.S. EPA optimal control pollutants $(\mathrm{H})$, whether as priority pollutants (I) in China, whether as persistent pollutant $(\mathrm{J}) 10$ weighting factor on listing potential pollutants in large liaohe yingkou screening.
In this paper, 39 potential pollutants in yingkou section of daliaohe river were evaluated and their comprehensive scores were calculated. The first 12 pollutants were selected as the optimal control pollutants in yingkou section of daliaohe river. The 10 weight factors were assigned weights of $18,12,12,10,18,5,4,5,8,8$ according to their influence degree. Among them, the potential hazard index is divided into 18 total points, and the potential hazard index of other pollutants is determined according to the proportion of 20 points accounted for by the highest potential hazard index. The pollutant migration is based on the adsorption coefficient (Kd) size in the gas inclusion zone and aquifer medium, while the degradation is characterized by the half-life $\left(T_{1 / 2}\right)$ size in water, as shown in table 3 .

Table3. weight and score of screening indicators

\begin{tabular}{ccccccc}
\hline Assignment & 18 & 15 & 2 & 9 & 6 & 3 \\
\hline Mobility & $2>\mathrm{Kd}$ & $4>\mathrm{Kd}>2$ & $6>\mathrm{Kd}>4$ & $8>\mathrm{Kd}>6$ & $10>\mathrm{Kd}>8$ & $\mathrm{Kd}>10$ \\
Assignment & 12 & 10 & 8 & 6 & 4 & 2 \\
Degradability & $\mathrm{T}_{1 / 2}>50$ & $50>\mathrm{T}_{1 / 2}>40$ & $40>\mathrm{T}_{1 / 2}>30$ & $30>\mathrm{T}_{1 / 2}>20$ & $20>\mathrm{T}_{1 / 2}>10$ & $10>\mathrm{T}_{1 / 2}$ \\
\hline
\end{tabular}

\section{Screening results of optimal pollutant
control in yingkou section of daliaohe 3 Screening results of optimal pollutant
control in yingkou section of daliaohe river}

Table4. comprehensive assessment table for optimal control pollutants

\begin{tabular}{|c|c|c|c|c|c|c|c|c|c|c|c|c|}
\hline Number & Pollutant name & $\mathrm{A}$ & $\mathrm{B}$ & $\mathrm{C}$ & $\mathrm{D}$ & $\mathrm{E}$ & $\mathrm{F}$ & $\mathrm{G}$ & $\mathrm{H}$ & I & $\mathrm{J}$ & Total \\
\hline 1 & $\mathrm{Cd}$ & 18 & 12 & 12 & 6 & 20 & 5 & 4 & 5 & 8 & 8 & 98 \\
\hline 2 & $\mathrm{Cr}$ & 18 & 12 & 12 & 6 & 20 & 5 & 4 & 5 & 8 & 8 & 98 \\
\hline 3 & $\mathrm{~Pb}$ & 18 & 12 & 12 & 6 & 15 & 5 & 4 & 5 & 8 & 8 & 93 \\
\hline 4 & $\mathrm{Cu}$ & 18 & 12 & 12 & 6 & 14 & 5 & 4 & 5 & 8 & 8 & 92 \\
\hline 5 & $\mathrm{Zn}$ & 18 & 12 & 12 & 0 & ? & 5 & 4 & 5 & 8 & 8 & 72 \\
\hline 6 & 1, 3-dinitrobenzene & 18 & 12 & 12 & 2 & 15 & 5 & 0 & 0 & 0 & 0 & 64 \\
\hline 7 & O-dimethyl dibutyl ester & 18 & 12 & 0 & 6 & 10 & 0 & 4 & 5 & 8 & 0 & 63 \\
\hline 8 & O-dimethyl din-octyl ester & 18 & 12 & 0 & 6 & 10 & 0 & 4 & 5 & 8 & 0 & 63 \\
\hline 9 & 2-nitrotoluene & 18 & 12 & 0 & 6 & 8 & 5 & 0 & 5 & 8 & 0 & 62 \\
\hline 10 & 1, 4-dinitrobenzene & 18 & 12 & 12 & 0 & 15 & 5 & 0 & 0 & 0 & 0 & 62 \\
\hline 11 & nitrobenzene & 18 & 12 & 12 & 4 & 11 & 5 & 0 & 0 & 0 & 0 & 62 \\
\hline 12 & 2-methyl-4, 6-dinitrotoluene & 18 & 12 & 12 & 2 & 11 & 5 & 0 & 0 & 0 & 0 & 60 \\
\hline 14 & Dimethyl phthalate & 18 & 12 & 0 & 6 & 7 & 5 & 4 & 5 & 0 & 0 & 57 \\
\hline 15 & 4-nitrotoluene & 18 & 12 & 12 & 2 & 7 & 5 & 0 & 0 & 0 & 0 & 56 \\
\hline
\end{tabular}

Note: ?Indicates that there is no relevant data

From the screening results, it can be concluded that there are 12 kinds of pollutants in daliaohe, including heavy metal cadmium, chromium, lead, copper, zinc, 1, 3dinitrobenzene, o-dimethyl dibutyl ester, o-dimethyl dinoctyl ester, 2-nitrotoluene, 1, 4-dinitrobenzene, nitrobenzene, 2-methyl-4, 6-dinitrotoluene.

\section{Conclusion}

In this paper, an improved comprehensive scoring method with 10 weight factors of pollutants as screening indexes is proposed to screen the optimal control pollutants in yingkou section of daliaohe river.In view of the optimal
After the comprehensive score of potential pollutants was calculated according to the comprehensive score method, the first 12 pollutants were selected as the optimal control pollutants in daliaohe river. The results are shown in table 4. 
their hard work and the students who helped me with this paper.

\section{Reference}

1. Ma Yingqun Qin Yanwen, bing-hui zheng, Yang Chenchen. Large liaohe main pollution source of heavy metal pollution characteristic and evaluation [A]. China environmental science society, environmental protection department of sarft, Harbin industrial university, Harbin normal university, nanjing institute of geography and limnology, Chinese academy of sciences. 2013, the ecological protection of water resources and water pollution control symposium [C]. China environmental science society, environmental protection department of sarft, Harbin industrial university, Harbin normal university, nanjing institute of geography and limnology, Chinese academy of sciences:, 2013-9.

2. chang $\mathrm{xu}$, ma yingqun, Yang chenchen, liu zhichao, cao wei. Heavy metal characteristics and pollution evaluation of major pollution sources in daliao river [J]. Environmental pollution and prevention,2015,3705:32-38.

3. Wang hui, sun lina, liu zhe, luo qing, wang xiaoxu, wu hao, sun jiajun. Pollution level and carcinogenic risk assessment of polycyclic aromatic hydrocarbons in surface water of daliaohe river [J]. Journal of ecotoxicology,2015,1004:187-194.

4. Xu qiujin, li li, liang cunzhen, cheng xiao-ying. Research on the selection of optimal control pollutants in rural drinking water source of a county in huai 'an [J]. Chinese journal of environmental sciences, 2013,3304:631-638.

5. Pei shuwei, zhou junli, liu zhengtao. Research progress in the screening of environmental optimal control pollutants [J]. Journal of environmental engineering and technology,2013,304:363-368. 